\title{
FOREWORD
}

\section{A users' guide to the 2016 Surviving Sepsis Guidelines}

\author{
R. Phillip Dellinger ${ }^{{ }^{*}}$, Christa A. Schorr ${ }^{1}$ and Mitchell M. Levy ${ }^{2}$
}

() 2017 SCCM and ESICM

The 2016 Surviving Sepsis Guidelines have arrived, a remarkable document, all 74 pages with 655 references $[1,2]$. We congratulate the lead authors and contributing committee members. With each iteration, the guidelines grow more complex and perhaps more challenging to utilize. Herein, we offer guidance toward effective utilization.

\section{Layers of the guidelines}

The guidelines may be thought of as several concentric layers, similar to an onion (Fig. 1).

The outer layer represents the recommendations. A bedside practitioner responsible for immediate decision making and trusting guidelines process will focus on the recommendations. This group of users may find the tables of abbreviated recommendations-the essence of the guidelines condensed to seven pages-especially useful.

The next layer represents the rationales for the recommendations, illuminating the logic - the evidence and the thought-underlying each recommendation. For those who want a more in-depth understanding of how the recommendations were built, the rationales are a great resource. Moreover, the rationales help cement the recommendations for the busy practitioner: insight into the biologic plausibility and reasoning enable timely recall. The rationales also represent a foundation for educating healthcare practitioners on the recognition and treatment of sepsis.

The deepest layer, the core of the onion, houses the evidentiary tables. The tables compile and organize the

\footnotetext{
*Correspondence: Dellinger-Phil@CooperHealth.edu

${ }^{1}$ Cooper University Health and Cooper Medical School of Rowan University, Camden, NJ, USA

Full author information is available at the end of the article

This editorial is to be co-published in Intensive Care Medicine and Critical Care Medicine (DOI: 10.1097/CCM.0000000000002257)
}

existing data in a manner that provides insight into the reasoning behind each recommendation (magnitude of benefit or harm and the quality of evidence). This layer is typically for the inquisitive clinician and for the clinical scientist with focused interest in sepsis.

\section{Guidelines as a resource}

The collected guidelines are a resource document applicable to a variety of areas of sepsis management. Some areas are broad, such as initial resuscitation. Some areas are narrow, such as empiric therapy of a potential fungal infection. Inspection and reflection will provide insight into what can be stated with confidence and-equally important-where opportunities for future research lie.

The guidelines also tell a story about the approach to treating the sepsis patient through a management continuum beginning with diagnosis, initial resuscitation, antimicrobial therapy, source control, fluid/vasoactive therapy, and progressing through organ support and adjunctive therapy recommendations.

Two aspects of the guidelines should be understood. We illuminate these two aspects through an analysis of the priority currently assigned to early identification and initial treatment of sepsis, including antibiotics and fluid therapy.

First, the recommendation for antibiotic administration within an hour of diagnosis of sepsis is a lofty goal of care, judged to be ideal for the patient but not yet standard care. Despite the best intentions of the healthcare team, antibiotic administration within $1 \mathrm{~h}$ from time of diagnosis may be difficult due to the complexity of the hospital environment and essential care being delivered to other patients during the same time period by the same healthcare practitioners and health system. This is one among several "aspirational recommendations" considered by the experts to represent best practice that individual practitioners and healthcare teams should strive to operationalize.

\section{实




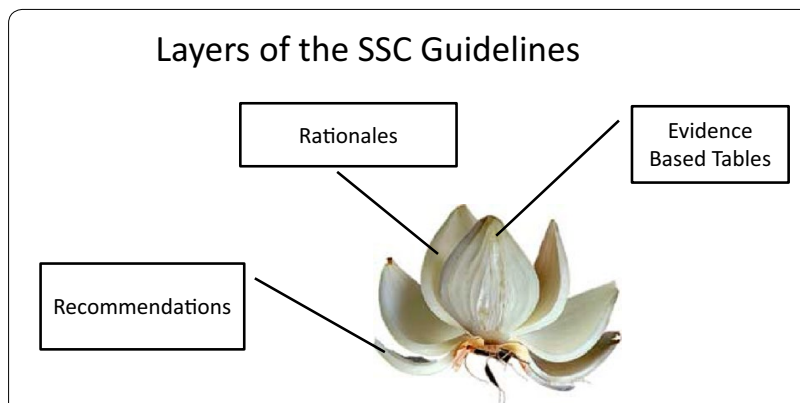

Fig. 1 The layers of an onion are paralleled to the components of the guidelines document, reflecting the depth of exploration by the user

Second, the clinician may push back from use of recommendations for fear that evidence-based guidelines lead to "cookie cutter" medicine and reflexive behaviors that deemphasize the "art" of medicine. The recommendations are intended for a "typical" septic patient. Patients still benefit from the art of medicine, which includes interpretation of data and individualization of treatment. The recommendations provide muchneeded general treatment guidance to the bedside decision maker who is busy, pressured to see more patients in less time, and who will use a distillation of the current literature into a coherent set of recommendations suitable for the large majority of septic patients who are "typical". For most of us in the trenches of everyday care, the lists of specific recommendations (seen in the tables in the manuscript) are a welcome adjunct to personalizing care.

This guidance includes sepsis management in the emergency department, the general hospital floors, and the ICU. For example, the recommendation for an initial $30 \mathrm{~mL} / \mathrm{kg}$ crystalloid infusion for tissue hypoperfusion is chosen as a one value fit for bedside guidance.

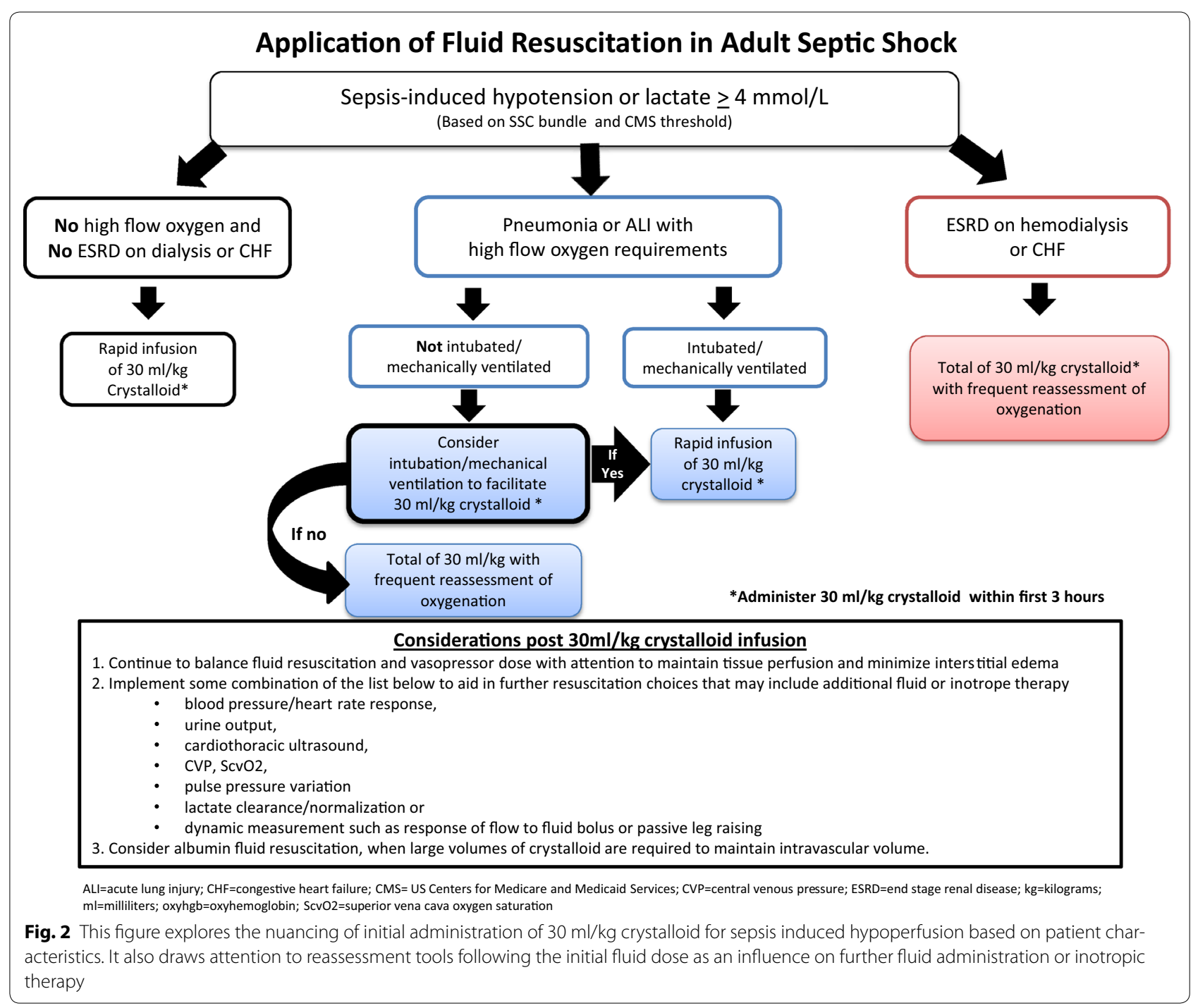




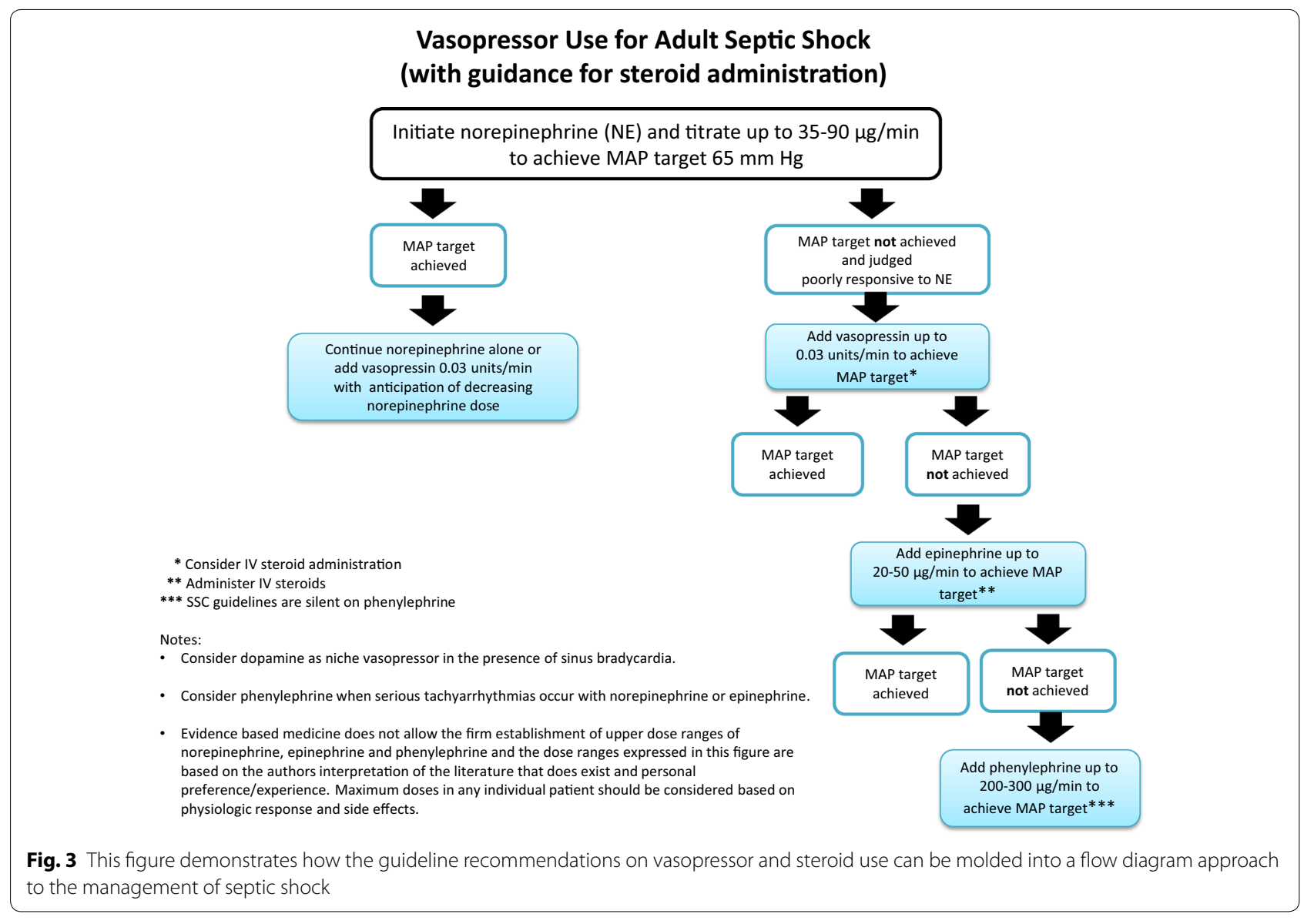

Administering $30 \mathrm{~mL} / \mathrm{kg}$ crystalloid is a useful initial therapy for the majority of patients and this literature supported fluid dose is linked to good outcomes [3, 4]. Figure 2 offers guidance for initial fluid resuscitation and is built forward from the guidelines recommendation for $30 \mathrm{~mL} / \mathrm{kg}$ initial crystalloid fluid administration within the first six hours for sepsis-induced tissue hypoperfusion. The flow diagram incorporates some of our own opinions for successful fluid resuscitation based on experience and our understanding of the literature.

Another illustration is the recommendation for an initial mean arterial pressure target of septic shock of $65 \mathrm{~mm} \mathrm{Hg}-$ a solid initial target with significant literature support-yet clearly one size does not fit all. Having a mean blood pressure target for the "typical" patient enables the art of medicine and provides a rationale for the provider in choosing a higher target for the atypical patient. Thus higher-than-reference values could-and perhaps even should-be selected for the patient with chronic poorly controlled hypertension, intra-abdominal compartment syndrome, or high central venous pressure (CVP) with acute decrease in renal perfusion [5-7].

\section{Values of the recommendations}

What about strong versus weak recommendations? Strong recommendations should be included as part of usual care of the septic patient. Weak recommendations imply that although the majority of well-informed patients or surrogate decision makers would want this done, others would not. Recognizing the complexity of many septic patients-heterogeneity of disease process and co-morbidities-one may arrive at the conclusion that in a particular patient, even a strong recommendation may not be in that patient's best interest.

What does the quality of evidence communicate that the strength of recommendation does not? The quality of evidence reflects the experts' confidence in the recommendation: high quality evidence generally means that the experts have high confidence in the recommendation while low quality evidence reflects lower confidence in the recommendation. The quality of evidence is an important determinant of the strength of recommendation ("strong, do it" or "weak, probably do it" recommendation). Substantial insight may be offered by the quality of evidence for the scientist searching for more 
Approach to SSC Guidelines Assessment

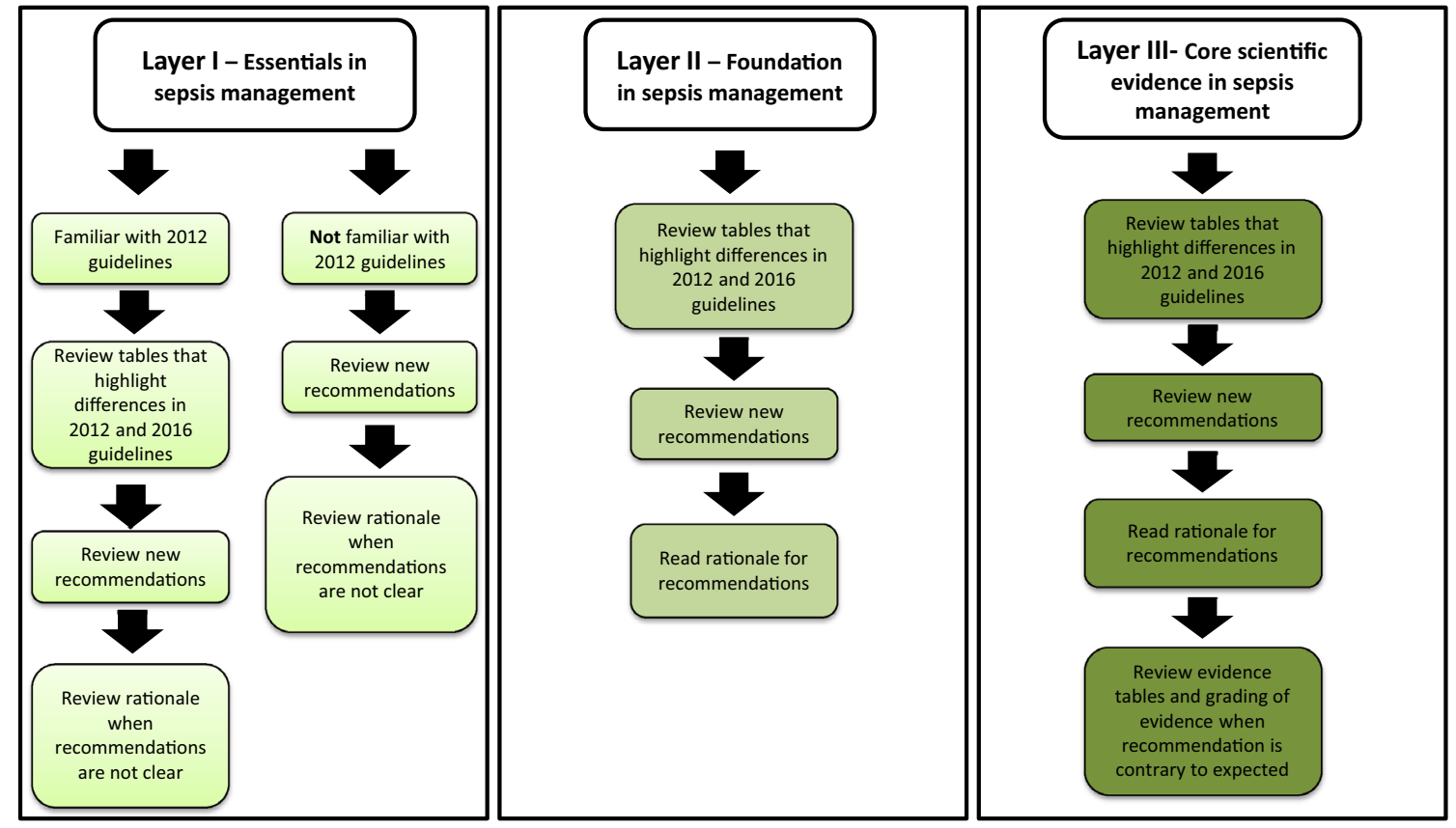

Fig. 4 This figure demonstrates how the guidelines document can be utilized to satisfy the needs of multiple categories of users

information as to how he or she will use the recommendation to generate hypotheses for research.

How should a clinician use the best practice statement (BPS) recommendations? These are strong recommendations that lack evidence-based literature that likely will never be available because they are common sense-generally accepted good things to do for septic patients. For example, recommending that sepsis and septic shock treatment and resuscitation should begin immediately is common-sense good practice, and the alternative is implausible. BPS recommendations are also typically very low risk. BPS recommendations are formulated based on strict criteria, therefore, should be considered at least as strong as the strong recommendations.

Recommendations for resuscitation targets have gone from clear but controversial in 2012 to nuanced in the 2016 guidelines. Gone in 2016 are the specific targets of CVP and $\mathrm{ScvO}_{2}$ to determine success of resuscitation, replaced with more general guidance as to a variety of targets (with emphasis on dynamic targets) that can be used. This is appropriate as it reflects the current lack of evidence as to a preferred target or approach to hemodynamic monitoring that deliver better clinical outcomes in sepsis $[3,4,8]$. Because a preferred target is not known, a variety of reassessment options after $30 \mathrm{ml} / \mathrm{kg}$ crystalloid fluid administration should be considered.

\section{Application of recommenations}

All guidelines lead to questions. Here are a couple of common ones, and our personal approaches.

Question 1: "It is pretty clear that I should start out using norepinephrine as my initial vasopressor in septic shock-but where do I go from there using the other vasopressor recommendations?" Figure 3 offers guidance in this area and is constructed in compliance with the guidelines vasopressor recommendations.

Question 2: "When is my patient considered "hemodynamically unstable" after fluid administration and vasopressor initiation, as to warrant steroid administration?" A useful parallel here is the use of an inhaled selective pulmonary vasodilator in the severest of acute respiratory distress syndrome patients. This therapy improves oxygenation but does not improve outcome in multiple large randomized trials $[9,10]$. The same is true for trials of steroids for septic shock, which despite producing improvement in hemodynamics have no consistent positive effect on patient-important outcome [11, 12]. So, consider these two low-risk therapies if there is concern that the patient will die of hypoxemia (acute respiratory distress syndrome) or hemodynamic instability (septic shock). Figure 3 incorporates steroid administration guidance into a vasopressor in septic shock flow diagram. 
In closing, it is important to remember that the guidelines can be many things to many different user groups. As guidance for the variety of users of the guidelines we offer Fig. 4 as an approach to uncover the onion.

Enjoy your guidelines adventure!

\section{Author details}

${ }^{1}$ Cooper University Health and Cooper Medical School of Rowan University, Camden, NJ, USA. ${ }^{2}$ Rhode Island Hospital and Brown University, Providence, $\mathrm{RI}, \mathrm{USA}$.

\section{Acknowledgements}

Gordon H. Guyatt OC, FRSC, Hamilton, Ontario, Canada for the concept of the guidelines process parallel to layers of an onion.

\section{Compliance with ethical standards}

\section{Conflicts of interest}

None.

Received: 4 January 2017 Accepted: 5 January 2017

Published online: 18 January 2017
3. Peake SL, Delaney A, Bailey M, Bellomo R, Cameron PA, Cooper DJ et al (2014) Goal-directed resuscitation for patients with early septic shock. New Eng J Med 371(16):1496-1506

4. Yealy DM, Kellum JA, Huang DT et al (2014) A randomized trial of protocol-based care for early septic shock. New Eng J Med 370(18):1683-1693

5. Asfar P, Meziani F, Hamel JF et al (2014) High versus low blood-pressure target in patients with septic shock. New Eng J Med 370(17):1583-1593

6. Cheatham ML, White MW, Sagraves SG, Johnson JL, Block EF (2000) Abdominal perfusion pressure: a superior parameter in the assessment of intra-abdominal hypertension. J Traum Inj Inf Crit Care 49(4):621-627

7. Kato R (2015) Pinsky MR personalizing blood pressure management in septic shock. Ann Int Care 5(1):1

8. Mouncey PR, Osborn TM, Power GS et al (2015) Trial of early, goal-directed resuscitation for septic shock. New Eng J Med 372(14):1301-1311

9. Dellinger RP, Zimmerman JL, Taylor RW et al (1998) Effects of inhaled nitric oxide in patients with acute respiratory distress syndrome: results of a randomized phase II trial. Crit Care Med 26:15-23

10. Taylor RW, Zimmerman JL, Dellinger RP et al (2004) Low-dose inhaled nitric oxide in patients with acute lung injury. JAMA 291:1603-1609

11. Annane D, Sebille V, Charpentier C et al (2002) Effect of treatment with low doses of hydrocortisone and fludrocortisone on mortality in patients with septic shock. JAMA 288(7):862-871

12. Sprung CL, Annane D, Keh D et al (2008) Hydrocortisone therapy for patients with septic shock. New Engl J Med 358(2):111-124

\section{References}

1. Rhodes A, Evans LE, Alhazzani W et al (2017) Surviving sepsis campaign: international guidelines for the management of sepsis and septic shock-2016. Crit Care Med. doi:10.1097/CCM.0000000000002255

2. Rhodes A, Evans LE, Alhazzani W et al (2017) Surviving sepsis campaign: international guidelines for the management of sepsis and septic shock-2016. Int Care Med. doi:10.1007/s00134-017-4683-6 